\title{
Control del agua bajo el modelo de gestión por cuencas hidrológicas en México
}

\section{Water control under Watershed Management model in Mexico}

\author{
Lourdes Romero Navarrete* \\ Centro de Investigaciones y Estudios Superiores en Antropología Social, \\ Ciudad de México, México \\ ORCID: https://orcid.org/0000-0003-4292-8387 \\ Mónica Olvera Molina* \\ Universidad Nacional Autónoma de México, Ciudad de México, México \\ ORCID: https://orcid.org/0000-0002-5493-825I
}

ISSN-OI85-4259; e-ISSN: 2007-9I76 DoI: http://dx.doi.org/IO.28928/ri/862019/aoti/romeronavarretel/olveramolinam

\section{Resumen}

Este artículo estudia el modelo de gestión por cuencas hidrológicas, visto como un dispositivo de orden cognoscitivo y cultural, que percibe la cuenca como un espacio "natural", pero elude fuertemente las dinámicas de poder que influyen en su implementación. Con base en la desnaturalización de la cuenca propuesta por la Geografía crítica y la noción de gubernamentalidad de Michel Foucault, analiza el control ejercido por los actores económico-empresariales en el diseño de políticas públicas, a través de su inserción en la alta burocracia del agua y de los Consejos de Cuenca. Estos órganos están dispuestos en la Ley de Aguas Nacionales (1992), como espacios de concertación, pero, como muestra su integración en el largo plazo, se han configurado como instancias de legitimación de intereses particulares, vaciando de contenido, tanto la regionalización basada en los ciclos hidrológicos en el ámbito de la cuenca, como las políticas públicas - de y para los ciudadanos-, retroalimentando los problemas de abasto e inequidad en la distribución, a la vez que impactan negativamente los procesos hidrológicos que dicen atender. Los casos de estudio se refieren a la Ciudad de México, a la región de La Laguna, en los estados de Coahuila y Durango, y a los Valles Centrales de Oaxaca, todos ellos cruzados por graves problemáticas sociales y ambientales.

Palabras clave: agua, conflicto, inequidad, Consejos de Cuenca, gubernamentalidad.

\footnotetext{
Abstract

This article studies the Watershed Management model, seen as a device of cognitive and cultural order, which sees the basin as a natural' space, strongly avoiding power dynamics that influence the model implementation. Based on basin denaturation, proposed by the critical Geography and on the notion of governmentality of Michel Foucault, analyzes the control exercised by the economical actors in the design of public policies, to through its inclusion in the high water bureaucracy and in Basin Councils. The National Waters Law (1992), established these Councils for concertation, but as show its integration in the long time, they are instances of legitimation of particular interests. In this manner, both regionalization based on hydrological cycles in the area of the basin, and public policy - give and for citizen- feedback problems of supply and inequity in water distribution, at the same time impact negatively in hydrological processes that claim to attend. The cases of study refer to the Mexico City, the region of La Laguna, in the States of Coahuila and Durango, and de valleys of Central Oaxaca, all of them, crossed by serious social and environmental issues.
}

Key words: water, conflict, inequality, Basin Councils, Governmentality.

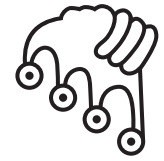

\section{IZTAPALAPA}

Agua sobre lajas

* lourdesr@ciesas.edu.mx **monicaom@comunidad. unam.mx / monicaolvera@oxfammexico.org 


\section{Introducción}

$L$ a gestión del agua por cuencas hidrológicas se instituyó en México por medio de la Ley de Aguas Nacionales de 1992; sin embargo, su trayectoria ha sido de largo plazo, marcada por la instauración de las Comisiones de Cuenca a mediados del siglo xx, siguiendo el modelo de la Tennessee Valley Authority (TVA) establecido durante el New Deal de los años treinta del siglo pasado en Estados Unidos (Melville, 2000). Este modelo, ahora bajo el paradigma de Gestión Integrada de los Recursos Hídricos (GIRH), se fundamenta en una racionalidad geográfica que percibe la cuenca como un espacio "natural" $y$, por ende, ahistórico, disociado fuertemente de los factores sociales. En contraste, su instrumentación muestra que se ha intervenido drásticamente en los procesos "naturales", a la vez que se ha exacerbado la sobrexplotación del hídrico y se ha impactado en su calidad y su disponibilidad. Pero no solamente, también revela que se ha privilegiado su valor económico, así como la política "ofertista" (González, 2016) basada en la construcción de grandes obras de infraestructura para el abasto, $y$ se ha relegado el cuidado de las fuentes propias, hechos que, en conjunto, prueban que la "cuenca" no es ahistórica y que la gestión a partir de este criterio obedece a un modelo económico que genera profundas asimetrías sociales y un uso dispendioso de los bienes naturales.

Con base en tres estudios de caso, planteamos que este paradigma opera a modo de dispositivo de orden cognoscitivo y cultural que permite dar viabilidad a una racionalidad política y económica, donde el espacio de las decisiones se encuentra fuertemente influido por los actores económico-empresariales, que intervienen en este caso a través de la alta burocracia y de los llamados Consejos de Cuenca, órganos de concertación social dispuestos por la ley, pero cuyas decisiones están supeditadas a las lógicas de poder entre los actores que participan en ellos. Los casos analizados corresponden, dentro del mapa administrativo sectorial, a las regiones hidrológico-administrativas: XIII. Aguas del Valle de México; viı. Cuencas Centrales del Norte, subregión Comarca Lagunera; y V. Pacífico Sur, las cuales tienen como entorno predominante la Ciudad de México, la región agroindustrial de la Comarca 
Lagunera y los valles centrales de Oaxaca, respectivamente. En todas existen severos problemas de acceso, disponibilidad, degradación, saneamiento y conflictividad, por lo que uno de los cuestionamientos que dieron pauta a este trabajo consiste en discernir sobre la pertinencia de asumir la escala cuenca como un criterio validado cientificamente, cuando en realidad son agentes sociales específicos, llámese grupos de interés económico y/o político, los que determinan las decisiones y acciones gubernamentales.

El artículo está dividido en cuatro apartados. En el primero, teórico, exponemos de qué forma la geografía crítica y la noción de gubernamentalidad de M. Foucault ofrecen herramientas sólidas para explicar las lógicas de poder político que se desarrollan en torno a la escala cuenca como unidad de gestión. Los siguientes apartados corresponden a los casos de estudio. Se enfatizan los datos que reflejan la problemática y el rol de los Consejos de Cuenca. A partir de esta información concluimos que tal como opera, la escala cuenca no ha logrado resolver los problemas en estos grandes cuerpos, y, en cambio, sí constituye una estrategia de control del espacio, a través de la cual se legitiman decisiones inequitativas, se estimulan lógicas de exclusión y se propician escenarios de conflicto y degradación ambiental.

\section{La gestión por cuencas desde la geografía crítica y la guberna- mentalidad foucaultiana}

El marco analítico utilizado en este trabajo procede de dos fuentes fundamentales: de autores identificados con la geografía crítica, la cual ha pugnado por analizar la producción social del espacio y por que se reconozca el papel de los agentes político-económicos en la producción de la naturaleza (Lefebvre, 1974; Harvey, 1974 y 2009; Swyngedouw, 2004a, 2004b), y en la noción foucaltiana de gubernamentalidad, recurso analítico crecientemente empleado por la geografía (Crampton y Elden, 2016; Rutherford y Rutherford, 2013; Legg, 2005; Philo, 2000) para identificar las estrategias que desde las estructuras del poder político intervienen en la gestión del espacio geográfico, y, por ende, en la administración de recursos como el agua.

\section{La bistoria cientifica pero muy política de la cuenca}

La historia científica de la cuenca ha sido política y polémica. Como concepto, ha superado la prueba del tiempo por varios motivos. En principio, porque se trata de un concepto básico, genérico, asequible, de fácil transmisión, pero sobre todo 
porque desde su origen estuvo apuntalado por los científicos cercanos al poder, que le imprimieron una singular capacidad para situarse de manera hegemónica. De ese modo, la cuenca ha fungido en diferentes momentos como catalizador político para legitimar políticas públicas, o bien para deslegitimar posturas o proyectos contrastantes.

Guillaume Delisle es el precursor de las regionalizaciones por cuencas gracias a su prolífico trabajo cartográfico y a su conocimiento de los grandes ríos europeos. Con ayuda del también cartógrafo y geógrafo Philippe Buache, Delisle estableció las primeras regionalizaciones por cuencas continentales europeas. Como primer geógrafo del rey de Francia en I729, a Buache se debe la teoría sistemática de las cuencas (I752), una de las primeras regionalizaciones universales, de modo que establecer parámetros a partir de una base fija y estática del territorio para la circulación del agua le proporcionó una amplia aceptación en la geografía y en disciplinas como la ingeniería. Así, la regionalización por cuencas se consideró como un criterio para explicar los fenómenos naturales, tales como las inundaciones y los temblores, o bien para la navegación, el comercio y la estrategia militar.

En I790, en plena eclosión revolucionaria, l'Assemblée nationale adoptó la racionalidad geográfica propuesta por Buache para decretar la creación de los departamentos franceses, adoptando una cuadrícula abstracta del territorio. Dicha regionalización administrativa es marcadamente topográfica, al distinguirse a través de los nombres de los ríos y las montañas (Mc Callam, 20II). Estas unidades pretendieron ser homogéneas con el fin de ofrecer un uso más práctico de la administración a los ahora ciudadanos de la república. Como afirma Melville (2000: 60), "el concepto de cuenca fluvial resultó útil para modernizar la administración pública y borrar las formas de gobierno del antiguo régimen".

De esta forma, la noción de cuenca se presentó como alternativa a la división política real, a la vez que se opuso al uso militar dado a los ríos por Luis XIV. La cuenca mostró, así, su capacidad política para deslegitimar el poder de un Estado y proveerla a otro, con lo que la "naturalización" del espacio a través de la regionalización por cuencas sirvió tanto para proyectos del antiguo régimen, como revolucionarios, logrando prontamente su hegemonía como división "natural".

Durante los siglos XVIII y xix, debido a la practicidad del concepto de cuenca, esta continuó gozando de una amplia aceptación tanto en la academia francesa como en la alemana. Paradójicamente, produjo más inquietudes que certezas para los precursores de lo que entonces empezó a definirse como geografía natural, pues tanto Alexander von Humboldt como Karl Ritter, icónicos naturalistas, señalaban que la cuenca francesa era una representación eurocéntrica que poco o nada tenía 
que ver con el verdadero espacio natural, por lo que la catalogaron como un conocimiento insuficiente para ser científico y fundamentalmente falto de trabajo empírico, en la medida en que desde su óptica no lograba validar su existencia natural. Sin embargo, en este campo de la geografía la noción de cuenca no desapareció como forma geográfica, solo se le dotó de nuevos contenidos, en otras palabras, la cuenca evolucionó, adoptó diferentes relieves y se le "llenó de vida" al considerar factores vegetales $y$ animales.

Por su parte, Friederich Ratzel (1885) se planteó una geografía política donde la cuenca asomó nuevamente su capacidad de neutralización política, al cuestionar la delimitación de las fronteras. Para Ratzel, la cuenca expresa de mejor manera la dinámica fronteriza al ser representada como una franja en vez de una línea, es decir, es una aproximación similar al acercamiento que hace actualmente la hidropolítica, vista como cuenca-frontera. ${ }^{1}$

Otra visión provino de Élisée Reclus, quien en Historie d' un Ruisseau (I869) presenta una geografía comparada, que estudia los arroyos en vez de las cuencas. A partir de este enfoque, Reclus planteó que la organización por cuencas de los grandes ríos procura recursos ideológicos y materiales al poder, por lo que su trabajo se propuso posicionar una geografía desenajenante de la enseñanza de la cuenca.

En la transición al siglo xx, el biólogo y urbanista Patrick Geddes hizo una síntesis de varios de los planteamientos previos en The valley section from bills to sea (1923). Esta obra representa el engrane entre el pasado y la visión contemporánea de la cuenca, que evoluciona en valle, describe sus perfiles geomorfológicos y continúa siendo funcional para la planeación, por lo que resulta una idea evolucionista, al ser utilizada desde el parteaguas hasta la costa por diferentes actividades productivas.

La elaboración de "la sección del valle" de Geddes deviene, así, en antecedente directo de la idea multifuncional del espacio, que dio pauta al programa de la TVA en 1933, es decir, se trata del proyecto que lanzó la planeación por cuencas como un modelo internacional de desarrollo, a la vez que comprendió la transformación radical de la geografía mundial del agua por medio de la construcción de megaproyectos de presas y cuya réplica llegó a México a través de las Comisiones de Cuenca a finales de la década de 1940.

En los años recientes, el debate en torno a la cuenca ha puesto el acento en la "desnaturalización" del agua. Un referente ineludible es el trabajo de Erick Swyngedouw (2004a y b), quien, entre otras tantas aportaciones, desarrolla la idea de un "ciclo hidrosocial del agua", donde la naturaleza no existe, lo que existe son híbri-

1 Véase el examen del concepto bidropolítica en Kauffer (2010). 
dos. El agua es un híbrido de la producción capitalista, en el que la hibridación se configura como un proceso de producción del agua, en un permanente convertirse en, o perpetua transgresión. En el ciclo hidro-social del agua, la producción de la naturaleza es el espacio, puesto que surge de la constante tensión dialéctica entre las decisiones y la lógica de hibridación. En todo momento se trata de un proceso histórico-espacial-político, en el que la circulación del agua la establecen las dinámicas del poder y donde el agua es metabolizada constantemente por la ciudad capitalista, haciendo que en el ciclo hidro-social del agua, esta fluya hacia el poder.

$\mathrm{El}$ poder atraviesa de igual forma la propuesta desnaturalizadora o el abordaje teórico-metodológico del grupo interdisciplinar de la red Justicia Hídrica, para el que toda naturaleza es social, impugnando la separación convencional entre naturaleza y sociedad (Zwarteveen y Boelens, 20I4). La naturaleza es social en términos tanto materiales como discursivos (Budds, 20II: 6I), por lo tanto, el poder no se limita a los ámbitos formales y oficiales de la toma de decisiones, sino que opera también a través de normas que ordinariamente se presentan como naturales o inevitables, de tal manera que la «normalización» y la «naturalización» a menudo sirven para legitimar y justificar la injusticia hídrica.

\section{La gubernamentalidad de Foucault}

La visión totalizadora del poder que abarca la producción de la naturaleza y lo que entendemos por natural, tiene en Michael Foucault un referente teórico puntual, particularmente a través de la noción de gubernamentalidad, herramienta analítica central para identificar las mediaciones político-culturales adosadas a las decisiones sobre el espacio y generadas por estructuras gubernamentales hegemónicas. Leído e interpretado renovadas veces, con el agregado semántico de las lenguas en que se ha traducido y de que el propio concepto fue paulatinamente trabajado por Foucault, la gubernamentalidad se presenta como un recurso teórico-metodológico para explicar los sofisticados y complejos procesos de los sujetos mismos para "gobernar" sus propias acciones, pero también para comprender cómo tales procesos están implicados en dispositivos culturales, que en un momento y espacio determinados operan en forma de instituciones jurídico-políticas, la biopolítica, entendida como el modo de conducir los comportamientos (conduct of conducts), en este caso, políticas gubernamentales que inciden y norman directamente en la vida de los individuos. En el caso que nos ocupa, la cuenca puede ser vista como un modelo asociado al 
poder-conocimiento, cuyo binomio ha actuado como un dispositivo cultural o estrategia de poder útil para validar políticas gubernamentales.

En Security, Territory, Population (2009), Foucault identifica la noción de gubernamentalidad como el "conjunto formado por instituciones, procedimientos, análisis y reflexiones, cálculos y tácticas que permiten el ejercicio de este poder específico, aunque muy complejo, que tiene la población como su objetivo, la economía política como su principal forma de conocimiento y los aparatos de seguridad como instrumento técnico esencial". En segundo lugar, identifica la gubernamentalidad como "la tendencia, la línea de fuerza, que, por largo tiempo en Occidente, ha llevado constantemente hacia la preeminencia sobre todos los otros tipos de poder -soberanía, disciplina, y así sucesivamente- del tipo de poder que podemos llamar 'gobierno' y que ha conducido al desarrollo de una serie de aparatos gubernamentales específicos (appareils) por un lado y, por otro, al desarrollo de una serie de conocimientos (savoirs)". En tercer lugar, se refiere a la gubernamentalidad como el"proceso, o, por el contrario, el resultado del proceso por el cual el estado de Justicia de la edad media se convirtió en el estado administrativo en los siglos xv y xvi y fue gradualmente 'gubernamentalizado"' (Foucault, 2009: 144).

Ponemos énfasis en la función del "conocimiento" (savoirs), en la adopción de una forma específica de racionalidad política, donde un tipo de saber se articula al poder jurídico-político para construir verdades que normalizan el conocimiento asumiéndolo como un criterio de validez de la práctica gubernamental. Este conocimiento implica no solo el terreno del saber sino el económico y el político, interfiriendo y modulando el dominio sobre la vida de los individuos, como brillantemente lo expresó en La verdad y las formas jurídicas (1996). En este sentido, para Foucault el propósito fundamental no consiste en establecer si es falso o verdadero un conocimiento determinado - que como ocurrió con las prisiones, métodos médicos, etc., que, afirma, probaron ser notoriamente falsos en numerosos casos- sino cómo este conocimiento llegó a ser un instrumento para el ejercicio del poder político, o, en términos de Foucault, cómo se relacionó el "régimen de verdad con la práctica gubernamental", proceso que denominó de "veridicción" (Foucault, 2007: 55). Foucault ejemplificó dicho proceso con el liberalismo del siglo xvirI, que identificó en el mercado el lugar de verdad o veridicción de los precios, de modo que lo que ocurría en este campo constituía un medio para la verificación o el falseamiento del ejercicio gubernamental, es decir, el mercado, siendo el principal instrumento de poder del Estado, apareció como el "lugar donde el gobierno debía buscar el principio de verdad de su práctica gubernamental" (Foucault, 2007: 49). 
Una estrecha asociación la encontramos en relación con los ciclos hidrológicos que se suceden en el marco de una cuenca, misma que se constituiría en el lugar de verdad de todo lo que ocurre alrededor del agua, es decir, el régimen de verdad para planear y decidir las acciones gubernamentales ha tenido la cuenca como uno de los principales referentes, que de este modo ha devenido en el principal criterio de validez de las políticas públicas con respecto al agua. Tal como afirma Margo Huxley, la gubernamentalidad foucaultiana aplicada al espacio geográfico muestra que las:

Racionalidades espaciales postulan cualidades causales de'entornos' y'espacios' como elementos en los fundamentos operativos del gobierno, que pueden examinarse como verdades que cuentan historias. Así, la escritura de historias de 'espacios' y 'poderes' (en plural) es también el examen de las lógicas contenidas en estrategias y tácticas del poder/gobierno que buscan usar el espacio con fines particulares (apud Foucault, 1980ः 149).

En la misma línea, para Rutherford y Rutherford (2013: 424) el territorio "es más que meramente tierra, es la representación del concepto emergente de 'espacio', como una categoría política: propiedad distribuida, mapeada, calculada, delimitada y controlada”. Por su parte, Stephen Legg (2005:147) plantea que la gubernamentalidad en su expresión epistemológica constituye uno de los campos donde las tecnologías de poder están asociadas con el uso de ciertos vocabularios y procedimientos que son utilizados en la producción de verdad, por lo que conocerlas lleva a cuestionarse sobre cuáles son las formas de "pensamiento, cálculo o racionalidad desplegadas, cómo se transforman en prácticas y cómo las específicas formas de gobierno surgen de específicas formas de verdad", proceso en el que también están implicadas las respuestas sociales en el momento en que problematizan o subvierten aquellos fundamentos gubernamentales. Este hecho resulta de gran trascendencia porque plantea las acciones colectivas reinvindicatorias, en este caso en torno al agua, como una forma de resistir los dispositivos culturales empleados desde la práctica gubernamental.

Ahora bien, determinar cómo la gubernamentalidad se ha expresado y operado en los hechos, tiene en Foucault un recurso metodológico fundamental, la genealogía o búsqueda del origen histórico de aquel régimen de verdad. ${ }^{2}$ El acercamiento

2 En Power and Knowledge (1980: II7), Foucault apunta: “....this is what I would call genealogy, that is, a form of history which can account for the constitution of knowledges, discourses, domains of objects, etc. whitout having to make reference to a subject which 
histórico planteado líneas arriba se encuadra en este abordaje, al mostrar cómo se fue construyendo este criterio de verdad sobre la "cuenca", el cual transcurrió de forma paralela al giro epistemológico del siglo xvir, sobre el ciclo hidrológico y la composición molecular del agua $\left(\mathrm{H}_{2} \mathrm{O}\right)$ (Linton, 20IO: 148), a través de los estudios pioneros de Pierre Perrault, Edmé Mariotte y Edmund Halley (Hubbart, 20II), formulando sendos conocimientos de la relación agua-ríos-cuenca-atmósfera (Deming, 2013; Dooge, 200I).

Esta revisión histórica muestra cómo el conocimiento del agua y demás elementos geográficos de la cuenca conformaron un poder-conocimiento que dio pauta a la escala cuenca como marco de organización de las actividades económicas, dotándole de una racionalidad económica favorable a la economía liberal, al mismo tiempo que política, al validar la acción gubernamental, que de esta manera ha funcionado como mediadora de los intereses que articulan este modelo económico en sus diversas escalas y especificidades locales. En suma, desde esta perspectiva, toda política sobre el agua comprende un poder económico e ideológico, que actúa sobre la sociedad a través de un marco interpretativo a partir del cual se construyen marcos de verdad que pretenden aprehender las lógicas que suceden en torno al agua, pero que en realidad enmascaran acciones de política pública que bajo el modelo económico actual están supeditados a la rentabilidad económica y al uso intensivo del recurso, resultan notoriamente excluyentes, están asociados a poderosos intereses económicos y promueven un uso dispendioso del agua.

\section{La gestión por cuencas en México}

En México las primeras acciones de gobierno enfocadas a las cuencas hidrológicas se remontan, justamente, al proceso de industrialización de los años cuarenta del siglo pasado, cuando se instituyeron las Comisiones de Cuenca vinculadas a los grandes proyectos hidroenergéticos. ${ }^{3}$ En 1992, la Ley de Aguas Nacionales instituyó la cuenca como la unidad de planeación y gestión del agua en todo el país (art. 3-IV). En 2004, con las reformas a esta ley se incorporó la Gestión Integrada de

is either trascendental in relation to the fields of events or runs in its empty sameness throughout the course of history".

3 Entre 1947 y 1960 se constituyen las comisiones de los ríos Papaloapan, Tepalcatepec, Lerma-Chapala-Santiago, Cuenca del Valle de México, río Fuerte, río Grijalva, río Pánuco y río Balsas. 
los Recursos Hídricos (GIRH), que, con base en la misma escala, integró diversos componentes ambientales y sociales al modelo de cuenca, ${ }^{4}$ cuyo resultado es una intrincada regionalización administrativa que incluye 13 regiones hidrológico-administrativas, a cargo de los respectivos Organismos de Cuenca, divididas en 37 regiones hidrológicas, con programas focalizados en distintos acuíferos y ríos a lo largo del territorio nacional (Conagua, 20I2a). Esta compleja estructura se superpone a la división política y a la operación de los tres niveles de gobierno (municipal, estatal y federal). Es decir, la complicada caracterización de la gestión por cuencas en realidad agrupa y superpone escalas, niveles de gobierno y diferentes condiciones ambientales, al tiempo que diversos entornos sociales y culturales.

Junto con el aparato administrativo requerido para la implementación de este esquema, que, en principio tuvo un objetivo descentralizador, la ley de 1992 dispuso mecanismos de participación a través de los Consejos de Cuenca (Hernández, 20II), a los que aquella legislación dedicó solo dos escuetos artículos, de los más de Ioo que comprende, identificándolos como instancias de coordinación y concertación entre la Comisión Nacional del Agua (Conagua), las dependencias y entidades de las instancias federal, estatal o municipal y los representantes de los usuarios de la respectiva cuenca hidrológica (art. 13). Hasta este momento se han instalado 26 Consejos de Cuenca (Conagua, 2017: 7).

En la integración de estos consejos, como se muestra en los casos que analizamos, es donde se concretó la paulatina captura del poder de decisión gubernamental por parte de agentes privados o grupos de interés económico, que, bajo el argumento de responder a la escala cuenca, basada en un conocimiento científico, no solo enmascaró la trasferencia del poder decisión del espacio público al privado -rasgo distintivo de las políticas neoliberales de aquellos años-, sino que se impuso en contextos locales, donde no necesariamente se comparte una visión de la naturaleza estructurada en torno a la cuenca; en el caso de localidades de tradición comunitaria, por ejemplo, este paradigma les ha forzado a modificar sus dinámicas culturales y sociales, supeditándolas a intereses extralocales.

A través de las reformas a la ley en 2004 se amplió significativamente el rubro "Consejos de Cuenca". Se puntualizó entre las funciones y atribuciones la de "discutir

4 La ley definió como cuenca hidrológica "el territorio donde las aguas fluyen al mar a través de una red de cauces que convergen en uno principal, o bien el territorio en donde las aguas forman una unidad autónoma o diferenciada de otras, aun sin que desemboquen en el mar. La cuenca, conjuntamente con los acuíferos, constituye la unidad de gestión del recurso hidráulico". 
las estrategias, prioridades, políticas, líneas de acción y criterios, para ser considerados en la planeación de corto, mediano y largo plazo de la cuenca hidrológica" (art. I3 bis I). Asimismo, se abundó en la forma de integración y organización, aunque la representación hasta el momento ha recaído fundamentalmente en usuarios portavoces de grandes grupos de interés, tanto nacional como internacional, y no representan los intereses de la diversidad de usuarios de una cuenca.

Por otra parte, aunque según el marco legal estos órganos no están subordinados a la Conagua, de facto su operación, su logística y en general las actividades asociadas al consejo son gestionadas y financiadas por este organismo. Esta condición, además, sitúa a los Consejos de Cuenca y a sus órganos auxiliares (entre ellos, los comités hidráulicos y los comités técnicos de aguas subterráneas) entre dos espacios, el público y el privado, donde se difumina el ejercicio soberano del Estado sobre un recurso de propiedad nacional, a la vez que se crean ambigüedades en cuanto a las responsabilidades particulares, en detrimento de la transparencia informativa y de un manejo adecuado del líquido. De igual forma, convertidos en arenas políticas, la disputa por las decisiones en torno al agua subsume al sector burocrático y técnico de la autoridad del agua (influido, a su vez, por la competencia político-partidaria) al peso de los actores políticos, ya sea federales, estatales y municipales, tanto como de los actores económicos y representantes de usuarios, o bien de la acción de los organismos civiles, académicos y ciudadanos, cuyo nivel de incidencia está definido por las coyunturas políticas y la conformación de redes.

Este panorama ha contribuido a que numerosas demandas sociales sean trasladadas al terreno jurisdiccional, que, como el caso de la Ciudad de México, han servido como espacios de disputa política, o como en el de Oaxaca, que veremos más adelante, donde el proceso legal emprendido por diversos pueblos contra la Conagua ha resultado largo y oneroso, y no necesariamente justo. No obstante, la demanda social se mantiene como un recurso que en el esquema foucaultiano se presenta como un espacio de resistencia, señalando problemáticas ambientales, despojos e inequidad, así como denunciando la estrecha asociación entre funcionarios públicos de alto nivel y el sector empresarial, nacional y/o extranjero, y en algunos casos ha logrado detener grandes proyectos hidráulicos.

Como lo refieren los tres casos analizados, cada proceso regional se desenvuelve a ritmos distintos, pero convergen en mostrar que la implementación de políticas bajo la escala cuenca puede ser caracterizado como el ejercicio de una gubernamentalidad que supedita el saber sobre la cuenca a una administración que privilegia la rentabilidad económica y el ámbito de los negocios privados asociados a usos específicos del agua, como pueden ser el urbano, agrícola, industrial o turístico, 
cuyas repercusiones engloban tanto comportamientos - hábitos de consumo y percepciones entre otros-, como impactos negativos sobre la sociedad y el ambiente.

\section{La Ciudad de México y su zona metropolitana}

Antecedida por una secular historia de centralidad política, la Ciudad de México y su zona metropolitana (zMVM), formada por municipios del Estado de México y de Hidalgo, es una de las urbes con mayores desafíos sociales y ambientales del mundo. De acuerdo con el indicador de Medición de Actividad Económica con Grandes Datos (MAGDA), la ZMVM concentra $25 \%$ de la actividad económica nacional ( $E l$ Economista, 2017). La Ciudad de México es la entidad con el piB más alto del país: aporta $16.4 \%$ (Conagua, 2014:22), en tanto la parte correspondiente al Estado de México integra algunos de los municipios industriales más importantes de la ZMVM, como Tlalnepantla, Naucalpan y Cuautitlán. La población de la metrópoli se calcula en 20 millones de habitantes, de los cuales alrededor de ocho corresponden a la Ciudad de México.

Localizada en un territorio de vocación lacustre, la ZMVM forma parte de la Región hidrológico administrativa xiır, denominada "Aguas del Valle de México", a cargo del Organismo de Cuenca del mismo nombre, cuya sede se asienta en la Ciudad de México, donde también reside el Consejo de Cuenca del Valle de México. La superficie de esta región asciende a $18229 \mathrm{~km}^{2}$, dividida en las subregiones Valle de México (mapa I) y Tula ${ }^{5}$ La primera se asienta en la Cuenca de México, denominada en distintos momentos como Cuenca del Valle de México (Conagua, 2016:2), cuya extensión es de $9700 \mathrm{~km}^{2}$ (Conagua, 2016:2). Del agua que abastece a la zona metropolitana, $56 \%$ procede de fuentes subterráneas (Conagua, 2016: I9), que se encuentran sobrexplotadas en 36 \% (вм/ConAgUA/ANEAS 20I3: XI), afectando especialmente al "Acuífero de la Zona Metropolitana del Valle de México", localizado al sur de la ciudad, con una extensión de $3448 \mathrm{~km}^{2}$ (Consejo Nacional de Investigación, I995: 33). Este acuífero presenta una recarga media anual de 512.8 $\mathrm{hm}^{3}$, con un déficit de -59I.I (Conagua, 2015a:2). Asimismo, el abasto de la región

5 En la subregión Valle de México se incluyen i6 delegaciones políticas, 50 municipios del Estado de México, I5 de Hidalgo y cuatro de Tlaxcala, en tanto, la subregión Tula la integran 12 municipios del Estado de México y 24 de Hidalgo (Conagua, 2013: 7). Cubre la Región Hidrológica del río Pánuco, cuenca del río Moctezuma, y cubre parte de las regiones hidrológicas de los ríos Balsas y Lerma. 
depende en alrededor de un tercio del trasvase realizado por los sistemas Lerma y Cutzamala (Conagua, 2016: 19), generando agudas problemáticas en las localidades de origen y un alto costo por las condiciones topográficas que atraviesa. Si bien el total del área involucra problemáticas de abasto, saneamiento, calidad, etc., estas se aglutinan en la Ciudad de México y en los municipios conurbados del Estado de México, que concentran prácticamente $70 \%$ de la población que habita la región. Es aquí donde un cúmulo de factores humanos y geográficos se conjuntan para centrar la problemática en el abasto urbano y en el saneamiento, factores que ponen en juego la viabilidad de esta gran urbe.

Mapa i Regiones Hidrológico Administrativas en México.

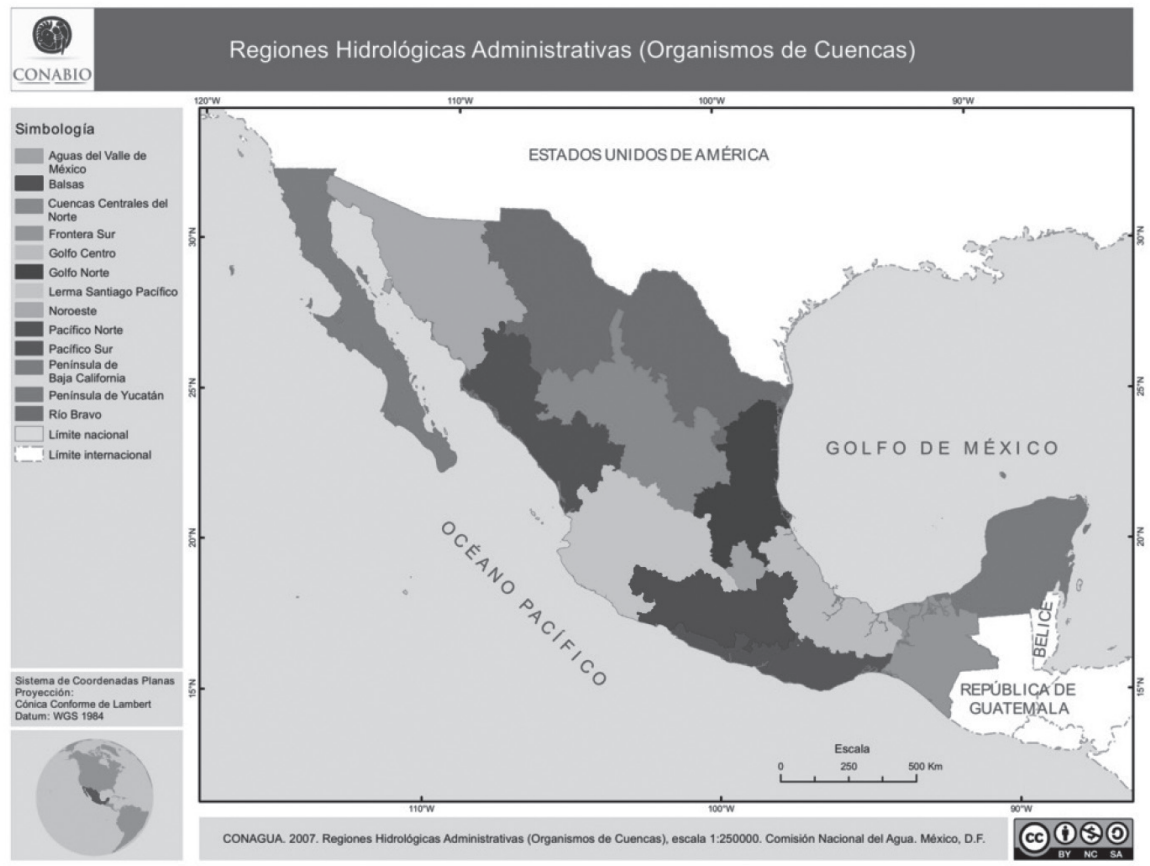

Fuente: CONABIO, 2018, con datos de Conagua, 2007.

En torno a los problemas del agua en la ZMVM se han generado ingentes volúmenes de estudios, programas y acciones. Los mayores focos de atención están puestos en los aspectos técnicos, geológicos y económicos, de los cuales se desprende la estrecha relación entre el impacto de la actividad económica, la composición de 
los suelos y las fuentes de agua y la dinámica que se genera entre ambos. Ángeles, Perevochtchikova y Carrillo (2008:40) advierten que el principal problema se sitúa en la falta de un enfoque sistémico que considere todas las variables ambientales, es decir, suelos, temperaturas, edafología y demás factores que intervienen en el flujo del agua subterránea.

En un estudio reciente, Arsenio González, examina la problemática bajo la perspectiva amplia que ofrece el concepto de región bidropolitana de la Ciudad de México, donde enfatiza la complejidad no identificada en el modelo de cuenca, pues la ZMvM se compone por:"Un sistema regional complejo, heterogéneo, de flujos entre lugares y zonas discontinuas, cuya escala ha rebasado las unidades político-administrativas y las unidades federales de manejo hidrológico (cuencas hidrológicas)" (González, 2016: 23). Al mismo tiempo, muestra la convergencia entre un saber técnico y una construcción simbólica vinculada a él, como factores sin los cuales no se explica la política de trasvase $y$, en general, la política que se ha venido aplicando al agua en la zмvм desde el siglo pasado.

En contraste, el programa Estrategia de Resiliencia de la $\operatorname{CDMX},{ }^{6}$ del propio gobierno de la ciudad, centra el problema en las fugas en el sistema de distribución (4I,4 \%), a la "expansión de la mancha urbana, al aumento de la población al interior de la ciudad [de México], así como a la falta de conciencia por parte de algunos sectores de la población sobre el impacto de su consumo excesivo".

La Conagua informa de la dimensión del problema: estima una demanda de 5 $286 \mathrm{hm}^{3}$ para 2030, en contraste con la oferta sustentable por capacidad instalada que aumentará a $3587 \mathrm{hm}^{3}$." Resulta entonces una brecha hídrica (oferta vs demanda) de $\mathrm{r} 699 \mathrm{hm}^{3}$ (Conagua, 2013: 38). Asimismo, calcula requerimientos financieros por I82 000 millones de pesos, de los cuales solo $12 \%$, se destinarían a incrementar la oferta y el resto a hacer eficiente al uso (mejor distribución y calidad). La Conagua considera requerimientos anuales por II ooo millones de pesos para los próximos 20 años. En suma, la inversión en infraestructura se mantendrá como uno de los negocios más rentables para las empresas constructoras del sector privado, que en los últimos años han estado lideradas por la Asociación Nacional de Empresas de Agua y Saneamiento (antas).

Esta íntima relación entre abasto de agua y construcción de infraestructura se ha concretado mediante recursos federales, locales e internacionales, pero de los que no se tiene información pública suficiente, como ocurre con el Fideicomiso 1928, para

6 Proyecto integrado a 100 resilience cities, que promueve la fundación Rockefeller (Gobierno de la Ciudad de México, 2016). 
apoyar el saneamiento en el Valle de México, constituido en 1996 por BANOBras, la Secretaría de Hacienda y Crédito Público y la Semarnat-Comisión Nacional del Agua como fiduciarios, capaces de recibir aportaciones de entes privados extranjeros y locales, y como fideicomitentes los gobiernos de la Ciudad de México y del Estado de México. Este instrumento ha sido clave en el otorgamiento de licitaciones de obra pública cuyos pormenores no han recibido la publicidad debida. ${ }^{7} \mathrm{La}$ fiscalización de los fideicomisos en México ha sido tema de un fuerte debate público, gracias al cual se ha logrado un conocimiento parcial sobre la forma de ejercer los recursos. En 2015, la SHCP dio a conocer cifras sobre fideicomisos que informan de la magnitud de los recursos que maneja el fideicomiso en cuestión, cuyos balances registraron rendimientos por más de 132000 millones de pesos (cuadro 2), para aquel año.

La captura de los espacios de decisión bajo el modelo de cuenca por parte del sector privado (empresariado) se realiza no solo a través de contratos millonarios, también participa en las altas escalas de la burocracia del agua y controla la mayor parte de las representaciones de los distintos usos del agua en el Consejo de Cuenca del Valle de México. ${ }^{8}$ Como muestran los cuadros I y 2, este control ha sido paulatino y se ha valido también del espacio judicial, donde la elite político-empresarial del Estado de México impulso entre 2004 y 2008 una demanda contra la Conagua y el Gobierno de la Ciudad de México que, como señala González (2016: 197), "la disputa respondió a un proceso articulado por las acciones de una elite política y una burocracia estatal que rebasaba las coyunturas electorales y respondía a una racionalidad geopolítica transexenal". Es así que las decisiones sobre el agua, cuyo espacio de legitimación está representado en los Consejos de Cuenca, están directamente relacionadas con el poder político y al negocio que representa el abasto de agua para la gran urbe.

7 En 2012, conocer las reglas de operación del Fideicomiso 1928 fue objeto de una solicitud de información ante el IfaI; la Secretaría de Finanzas del Distrito Federal (ente obligado) opuso una cláusula de confidencialidad (IFAI, 2OI2).

8 La participación privada en la gestión del hídrico existe desde 1983; diez años más tarde se creó el Sistema de Aguas de la Ciudad de México (SACMex) como organismo descentralizado con participación privada, constituyéndose en organismo desconcentrado en 2005. Desde 2006 empresas como SAPSA, IAXMEX, TECSA y ACSA operan en el manejo del agua, incluido el factoraje y la distribución en la red pública. 
Cuadro i. Consejo de Cuenca del Valle de México i998-20i7

\begin{tabular}{|c|c|c|c|c|c|c|}
\hline & 1998 & $2001-2005$ & 2010 & 2011 & $2012-2013$ & $2014-2017$ \\
\hline $\begin{array}{l}\text { C o m i t é } \\
\text { directivo } \\
\text { (presidente } \\
\text { del Consejo } \\
\text { de Cuenca } \\
\text { y como } \\
\text { secretario } \\
\text { Té c n i co } \\
\text { D i r } \\
\text { Organismo } \\
\text { de Cuenca) }\end{array}$ & $\begin{array}{l}\text { Dir. Gral. } \\
\text { Conagua }\end{array}$ & $\begin{array}{l}\text { Dir. Gral. } \\
\text { Conagua }\end{array}$ & $\begin{array}{l}\text { Dir. Gral. } \\
\text { Conagua }\end{array}$ & $\begin{array}{l}\text { Dir. Gral. } \\
\text { Conagua }\end{array}$ & $\begin{array}{l}\text { Dir. Gral } \\
\text { Conagua } \\
\text { D. Koren- } \\
\text { feld } \\
\text { (20I2-2015) } \\
\text { (Funcio- } \\
\text { nario en } \\
\text { el Edo. de } \\
\text { México, y } \\
\text { presidente } \\
\text { de Aneas } \\
\text { (2oo7-2oir, } \\
\text { que obtuvo } \\
\text { contratos } \\
\text { por + } 32 \\
\text { mdp). }\end{array}$ & $\begin{array}{l}\text { Rob e r to } \\
\text { Olivares } \\
\text { (Dir. Gral. } \\
\text { AnEAs, que } \\
\text { ha obte- } \\
\text { nido con- } \\
\text { tratos por } \\
\text { + Ioo mdp. }\end{array}$ \\
\hline & & \multicolumn{5}{|c|}{$\begin{array}{l}\text { Ramón Aguirre Díaz, Director de sacmex, presidente de } \\
\text { ANEAS, accionista de ENVIR EAU. }\end{array}$} \\
\hline Federales & & \multicolumn{5}{|c|}{ Semarnat, SHCP, SEDESO, SE, CFE, SS, Sagarpa } \\
\hline Estatales & & \multicolumn{5}{|c|}{ Ciudad de México y estados de Hidalgo y Tlaxcala } \\
\hline $\begin{array}{l}\text { Municipa- } \\
\text { les }\end{array}$ & & \multicolumn{5}{|c|}{$\begin{array}{l}\text { Incluye } 2 \text { I municipios y i } 6 \text { delegaciones de la Cd. de México. } \\
\text { Asiste un promedio de tres rep. }\end{array}$} \\
\hline & & \multicolumn{5}{|c|}{ Vocales usuarios } \\
\hline & \multicolumn{6}{|c|}{$\begin{array}{l}\text { Representantes provenientes de pequeñas organizaciones de productores } \\
\text { agrícolas, hasta los grandes empresarios constructores. } \\
\text { No hay una participación representativa de las organizaciones civiles o } \\
\text { instituciones académicas. }\end{array}$} \\
\hline
\end{tabular}

Fuente: Elaboración propia con base en datos hemerográficos y algunas actas del Consejo de Cuenca del Valle de México, cuyas copias fueron proporcionadas por la Coordinación de Atención a Emergencias y Consejos de Cuenca, Conagua, Ciudad de México, 2017.

CuAdro 2. Informe de la ShCP SObRe Fideicomisos Vigentes 2015.

\begin{tabular}{ll}
\hline RAмо / TIPo / ÁMBIто & Estatal \\
\hline $\mathrm{N}^{\circ}$ de casos & $\mathrm{I}$ \\
\hline Unidad Responsable coordinadora & Comisión Nacional del Agua \\
\hline
\end{tabular}




\begin{tabular}{ll}
\hline Fideicomitente & $\begin{array}{l}\text { Gobierno del Distrito Federal y Gobierno del Estado de } \\
\text { México. }\end{array}$ \\
\hline Clave de registro & 700016в00068 \\
\hline Denominación & $\begin{array}{l}\text { Fideicomiso irrevocable de administración y fuente de pago, } \\
\text { no. 1928,- para apoyar el proyecto de saneamiento del Valle } \\
\text { de México. }\end{array}$ \\
\hline Objeto & $\begin{array}{l}\text { Realizar las obras de infraestructura hidráulica en materia de } \\
\text { abastecimiento de agua potable, drenaje y saneamiento de la } \\
\text { ZMVM y su zona de influencia, incluyendo la protección de } \\
\text { acuíferos para propiciar su recarga y evitar su sobreexplotación, } \\
\text { conforme a las obras que autorice el comité técnico. }\end{array}$ \\
\hline Fiduciario o mandatario & BANOBRAS \\
\hline Grupo temático & Infraestructura \\
\hline Saldo final ejercicio anterior & $4,843,435,097.4 \mathrm{I}$ \\
\hline Ingresos (pesos) & I,928,585,909.68 \\
\hline Rendimientos & I3I,782,431.02 \\
\hline Egresos (pesos) & $2,440,86 \mathrm{I}, 786.94$ \\
\hline Fuente: Cuenta
\end{tabular}

Fuente: Cuenta de la Hacienda Pública Federal de 2015. México. p. 89.

\section{La Comarca Lagunera}

La Comarca Lagunera se asienta en la cuenca de los ríos Nazas y Aguanaval (4.7 millones de ha), área predominantemente árida de Coahuila y Durango, articulada por el cultivo algodonero desde el siglo xix y que experimentó una histórica reestructuración agraria en 1936, en cuyo contexto se formalizó el Distrito de Riego 017. Su población (2.7 millones) se concentra en la zona metropolitana de Torreón, Gómez Palacio, Ciudad Lerdo y Matamoros. Se ha posicionado como una cuenca lechera al albergar un hato ganadero de 600 ooo vacas, aproximadamente, y una producción diaria de alrededor de nueve millones de litros de leche (Sagarpa, 2015).

La composición geológica de los suelos, el ambiente árido y el patrón de cultivo forrajero ha dado lugar al abatimiento del acuífero principal, cuyo déficit es de alrededor de $-123.5 \mathrm{hm}^{3}$ (Conagua, 2015b: I). La sobrexplotación ha coadyuvado a la concentración de arsénico en el acuífero, haciendo de la arsenicosis un problema endémico. En este contexto, la disponibilidad y el deterioro en la calidad vinculados a la actividad agropecuaria intensiva constituyen el problema más importante para la comarca (DO, 20I4: 9). 
La comarca corresponde a la región Hidrológico-Administrativa viI, Cuencas Centrales del Norte (I87,62I km2), así como a la Región Hidrológica 36 (90 $829 \mathrm{~km}^{2}$ ) (Conagua, 2015 $: 14-20$ ). El área de injerencia del Consejo de Cuenca Nazas-Aguanaval cubre 2I municipios del estado de Durango, seis de Coahuila y cinco de Zacatecas (Conagua, 2017), extensión que equivale a $92896 \mathrm{~km}^{2}$. Sin embargo, la problemática se concentra en la subregión Comarca Lagunera (I 166 $\mathrm{km}^{2}$ ), específicamente en la zona metropolitana y el Distrito de Riego, cuya superficie sembrada para el ciclo 2013-2014 fue de 47845 ha (Conagua, 2015d: 24).

\section{Mapa 2. Ámbito de acción del Consejo de Cuenca Nazas-Aguanaval}

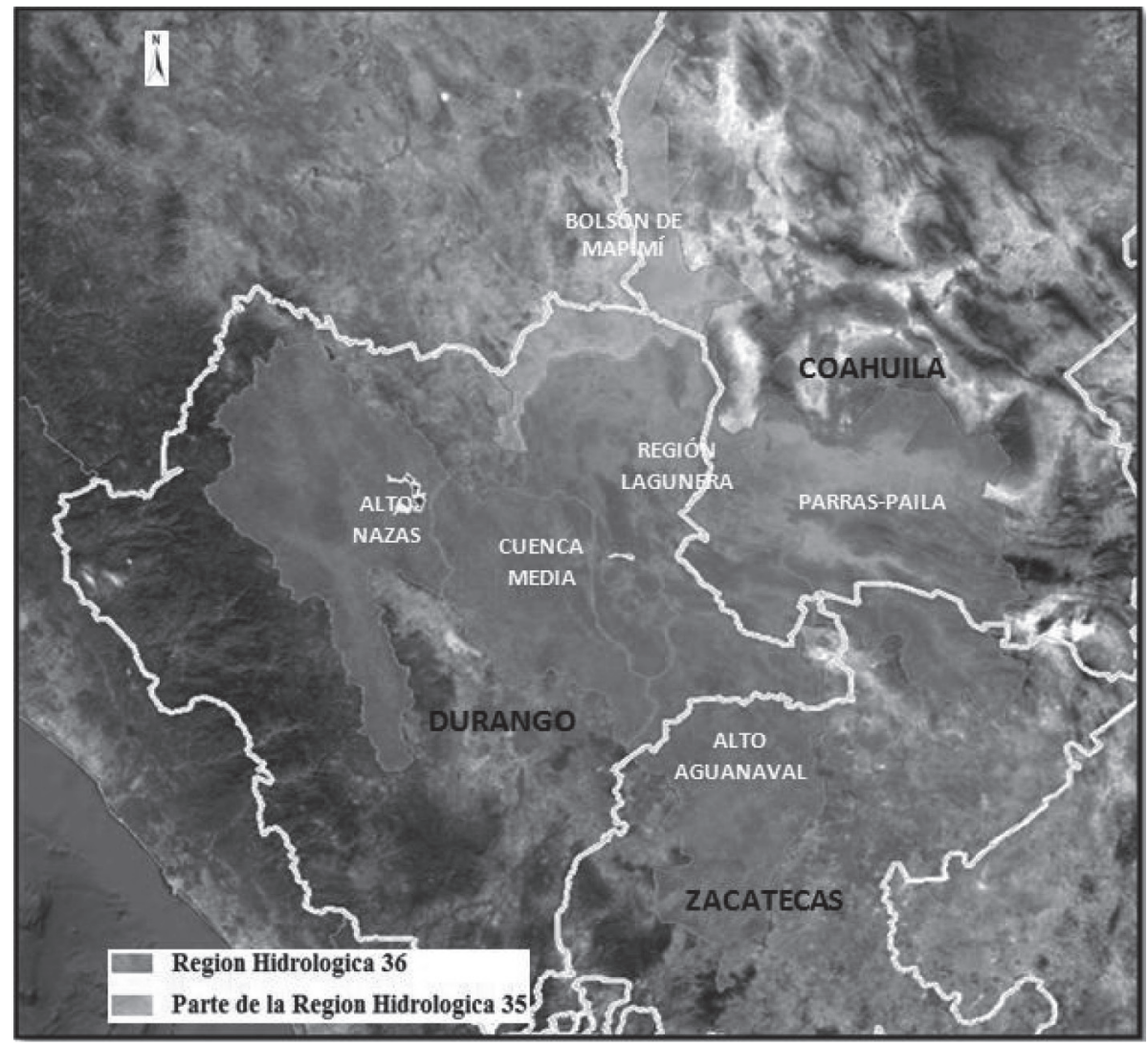

Fuente: Consejo de Cuenca Nazas-Aguanaval (2017) (http://cuencanazasaguanaval.org/) Consultado 23/02/2017. 
El Consejo de Cuenca Nazas-Aguanaval fue instalado en diciembre de 1998. Desde entonces los principales actores económicos han presidido los espacios de representación de los usos, agrícola, ganadero e industrial. Como se observa en el cuadro 3 , dicha representación ha estado a cargo sucesivamente de los principales accionistas de la primera empresa de lácteos del país, el Grupo Lala, que también obtuvo el control del Comité de Aguas Subterráneas del Acuífero Principal desde su instalación en el año 2000. Tanto la Cámara Agrícola Regional como la Unión Ganadera de la Región Lagunera han funcionado como actores cuyo peso específico ha delineado políticas y toma de decisiones. De manera paulatina, organizaciones civiles, como la coalición Encuentro Ciudadano Lagunero, han logrado constituirse en un contrapeso efectivo, que si bien no ha conseguido acciones contundentes en favor de un cambio en el patrón de consumo de agua, ha logrado mantener una presencia activa dentro del consejo de cuenca, cuya página web es de las más completas en el país. No obstante, familias como Gómez Ganem y Valdés Berlanga, del Grupo Lala, y Martín, del Grupo Soriana, se erigen como actores que además de fijar los límites de la acción estatal, han sido favorecidos por una política que persiste en un patrón de uso del agua que reiteradamente se ha mostrado como una amenaza para el entorno y los habitantes laguneros.

Rep de instituciones del Estado

$\begin{array}{ll}\text { CFE } & \text { Comisión Federal de Electricidad } \\ \text { OCCCN } & \text { Organismo de Cuenca Cuencas Centrales del Norte } \\ \text { SHCP } & \text { Secretaría de Hacienda y Crédito Público } \\ \text { SE } & \text { Secretaría de Economía } \\ \text { SS } & \text { Secretaría de Salud } \\ \text { Sagarpa } & \text { Secretaría de Agricultura, Pesca y Alimentación } \\ \text { SEDESO } & \text { Secretaría de Desarrollo Social } \\ \text { Semarnat } & \text { Secretaría de Medio Ambiente y Recursos Naturales }\end{array}$

Rep. de Cámaras y organizaciones empresariales agrícolas y pecuarios

$\begin{array}{ll}\text { AAgP } & \text { Asociación de Avicultores de Gómez Palacio } \\ \text { AARL } & \text { Asociación de Agricultores de la Región Lagunera } \\ \text { ACRL } & \text { Asociación de caprinocultores de la Región Lagunera } \\ \text { AGR } & \text { Asociación Ganadera Regional } \\ \text { CAGT } & \text { Cámara Agrícola y Ganadera de Torreón } \\ \text { CRA } & \text { Consejo Regional Agropecuario } \\ \text { IPNRN } & \text { Integradora de Productores de Nuez de la Región del Nazas }\end{array}$




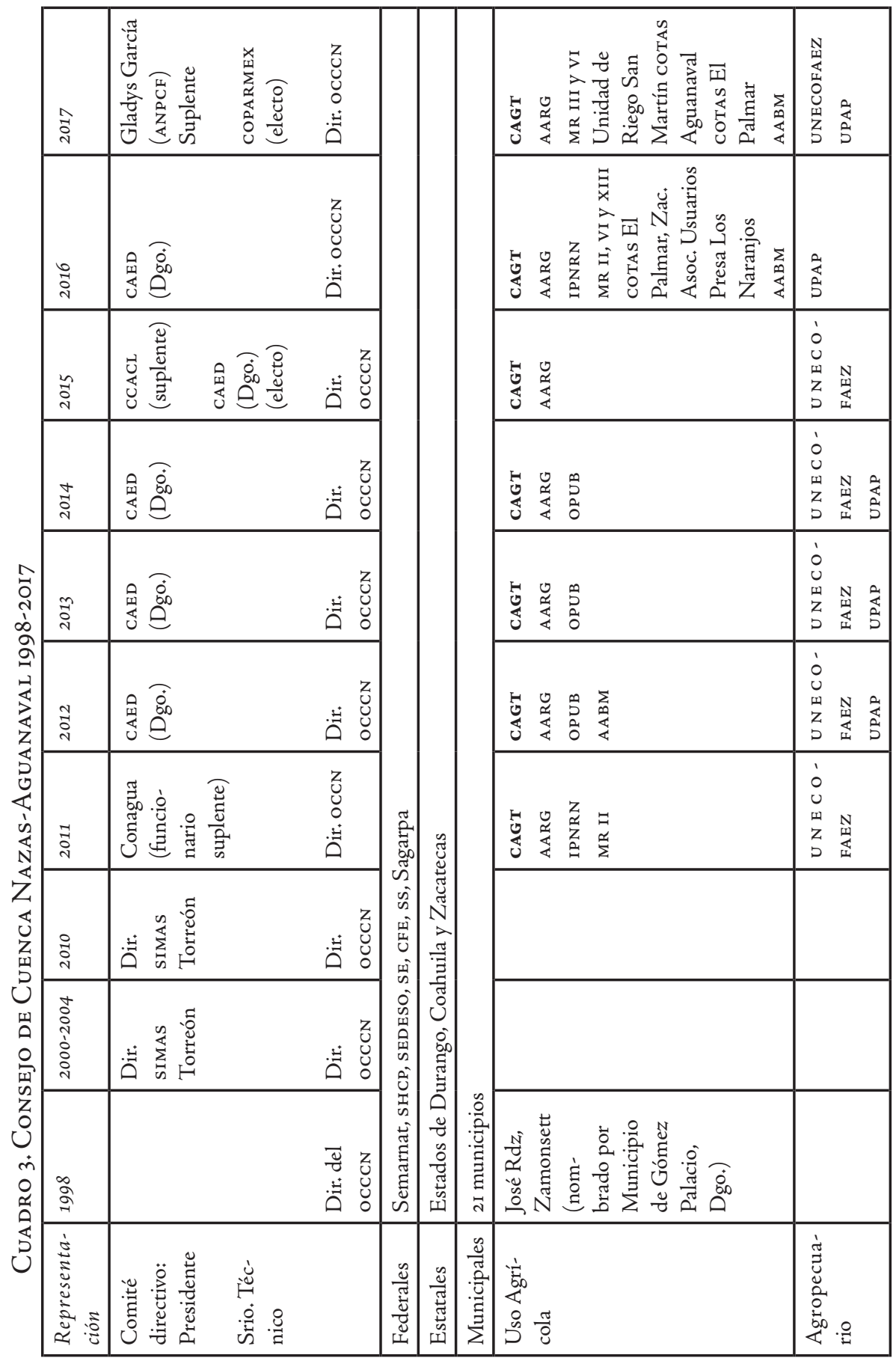




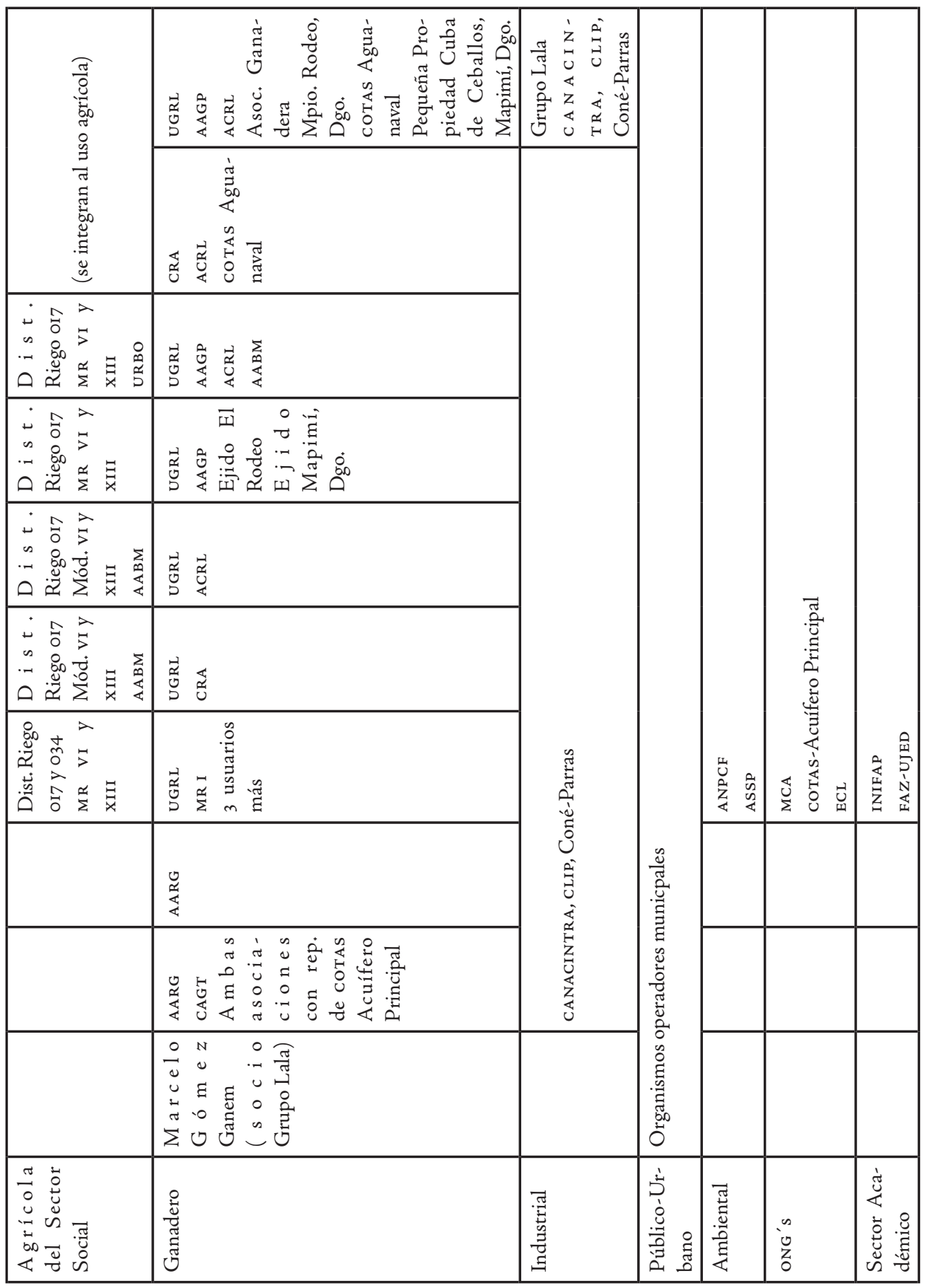


UGRL Unión Ganadera Regional de La Laguna

Rep. de Organizaciones de pequeños productores y/o ejidales

$\begin{array}{ll}\text { AABM } & \begin{array}{l}\text { Asociación de Agricultores del Bolsón de Mapimí } \\ \text { AglRg }\end{array} \\ \begin{array}{l}\text { Unecofociación Ganadera Local de Río Grande, Zac. } \\ \text { Zapata }\end{array} & \text { Unión de Ejidos y Comunidades Forestales y Agrícolas Emiliano } \\ \text { UPAP } & \text { Unión de Productores Agrícolas de Parras } \\ \text { URBo } & \text { Unidad de Riego Benjamín Ortega } \\ \text { OPUB } & \text { Organización de productores unidos de los Bajíos } \\ \text { SPRNP } & \text { Sociedad de Producción Rural de Nuez de Parras, Coah. }\end{array}$

Rep. de Ambientalistas/académicos

$\begin{array}{ll}\text { ANPCF } & \text { Área Natural Protegida Cañón de Fernández. } \\ \text { ASSP } & \text { Asociación de Silvicultores de San pedro, Coahuila. } \\ \text { ECL } & \text { Encuentro Ciudadano Lagunero } \\ \text { MCA } & \text { Movimiento Ciudadano por el Agua } \\ \text { INIFAP } & \text { Instituto Nacional de Investigaciones Forestales } \\ \text { UJED } & \text { Facultad de Agricultura y Zootecnia }\end{array}$

Rep. de Cámaras u organizaciones industriales

$\begin{array}{ll}\begin{array}{l}\text { CANACINTRA } \\ \text { COparmex }\end{array} & \begin{array}{l}\text { Cámara Nacional de la Industria de la Transformación } \\ \text { Mr }\end{array} \\ \text { Cotas } & \begin{array}{l}\text { Módulos de riego } \\ \text { Comités Técnicos de Agua Subterránea }\end{array}\end{array}$

\section{Los pueblos indígenas de Oaxaca y la defensa por el agua}

Oaxaca es un territorio ancestral para diversas poblaciones originarias. El caso que analizamos corresponde a 16 pueblos predominantemente zapotecos, de la región de los Valles Centrales, donde $54.4 \%$ de los municipios que albergan población indígena se ubican en el rango de alta marginación mientras que $45.5 \%$ presenta alta marginación (Coronel, 2006). 
La administración hidrológica de los valles centrales corresponde al Organismo de Cuenca Pacifico Sur $\left(77525 \mathrm{~km}^{2}\right)$ y al Consejo de Cuenca Costa de Oaxaca $\left(54,507 \mathrm{~km}^{2}\right)$. La superficie bajo el ámbito del Consejo equivale a $53.7 \%$ de la extensión del estado, concentrando $66 \%(2,509,294$ habs.) de la población total, así como 366 (64\%) de los 570 municipios del estado (Conagua, 20I4: II-20). Aquí está localizada la capital, Oaxaca, cuya población se aproxima a 260 ooo habitantes.

Para los i6 pueblos que han conformado la Coordinadora de Pueblos Unidos por el Cuidado y Defensa del Agua (COPUda), ${ }^{9}$ la regionalización administrativa de Conagua difiere de su Xnizaa ('nuestra agua', en lengua zapoteca), una microrregión cuyos habitantes demandan la modificación del decreto de veda del Acuífero Valles Centrales de Oaxaca, vigente desde 1967. Dicho acuífero abarca 3 769.44I $\mathrm{km}^{2}$, equivalente a $4.02 \%$ del área total del estado (OXFAM, 2015). El acuífero tiene instalado el Comité Técnico de Aguas Subterráneas de Valles Centrales A.C. (anrtes Valle de Zimatlán), donde los pueblos de Xnizza no han encontrado un espacio para la concertación ni solución de este conflicto. Como prácticamente todos los pueblos originarios del sureste mexicano, la organización de los pueblos del Xnizaa se basa en seculares usos y costumbres, reconocidos en la práctica pero de manera inconsistente por las instituciones gubernamentales.

Es importante remarcar que existen 146 vedas de agua subterránea vigentes en México, que comprenden cerca de $53 \%$ del territorio nacional, abarcando de manera total a I2 estados y en parte a los otros 20 (Conagua, 2010). Sin embargo, su aplicación es parcial, pues mientras el marco normativo vigente facilita el acceso al agua a las mineras, las comunidades indígenas enfrentan un entramado institucional, principalmente de Conagua, CFE y Sagarpa, discriminatorio y excluyente hacia estos pueblos, que les impide el legítimo disfrute del derecho al agua de los pueblos y las comunidades indígenas.

9 San Antonio Castillo Velasco, Santiago Apóstol, San Sebastián, San Jacinto Ocotlán, San Sebastián, San Jacinto Ocotlán, Santa Ana Zegache, San Isidro Ocotlán, San Pedro Mártir, San Pedro Apóstol, San Matías Chilazoa, San Felipe Apóstol, Tejas de Morelos, La Barda Paso de Piedras, San Martín Ticaljete, El Porvenir, Maguey Largo (copudA [s.a.]) 


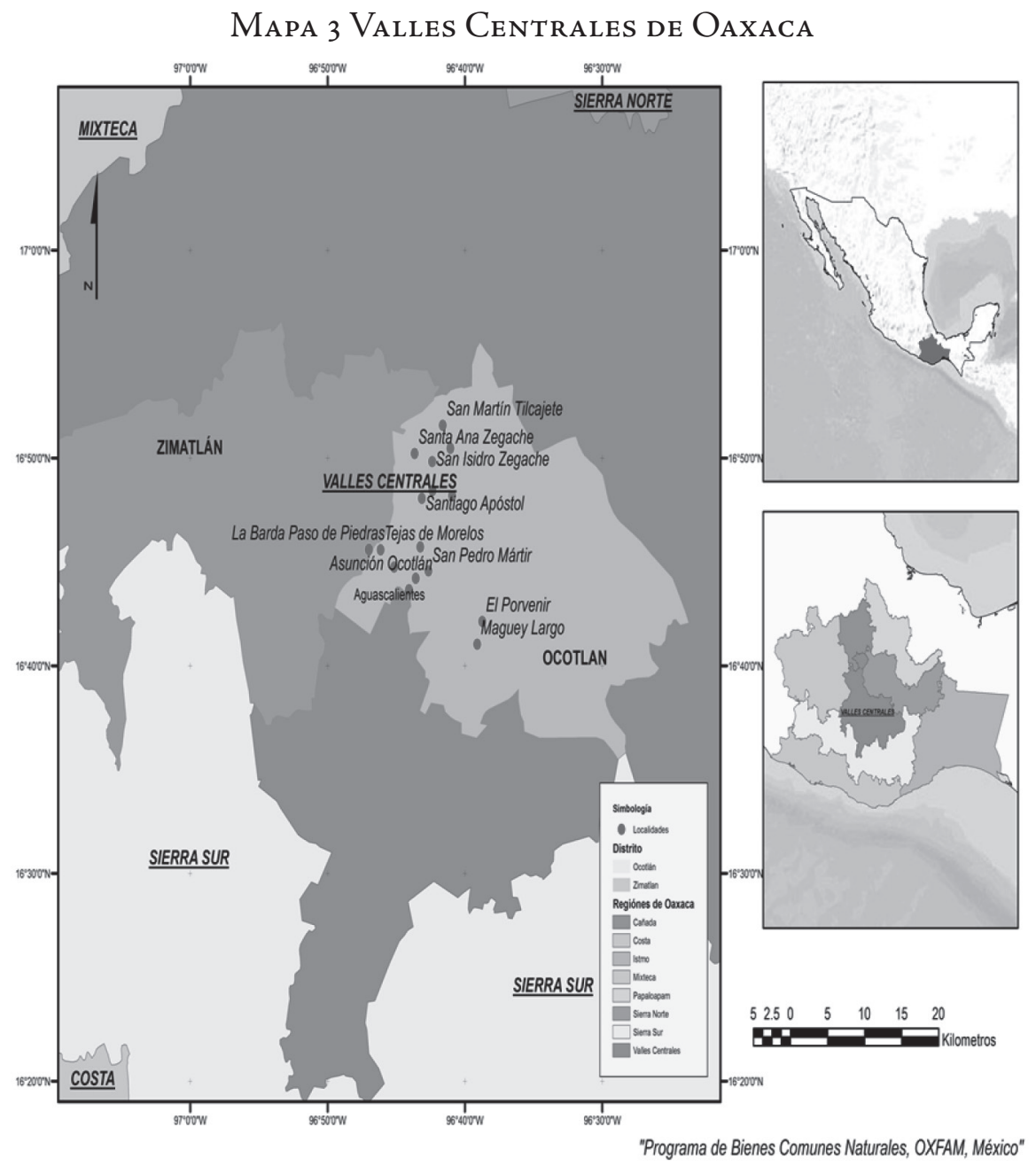

Fuente: Oxfam-México, Programa de Bienes Comunes Naturales.

La concesión es el mecanismo mediante el cual se regula el decreto de veda. En el 2005, durante la sequía reconocida como una de las más severas de la historia de Oaxaca, la Conagua otorgó títulos de concesión para pozos agrícolas asentando de manera precisa los volúmenes de extracción. Sin embargo, de manera discrecional el organismo comenzó a aplicar multas por gasto excedente de agua, calculándolo de manera indirecta con base en el consumo de energía eléctrica. En realidad, el mayor consumo de energía no significaba más volumen de agua, sino que se requería, para 
sacar la misma o menor cantidad de agua, llegar a mayor profundidad debido a la grave sequía de aquellos años. En su indignación, las 16 comunidades zapotecas afectadas por los cobros indebidos conformaron la COPUDA, al tiempo que refutaron las concesiones y su renovación. A ello se sumó el hecho de que Sagarpa y CFE restringieron el subsidio a las tarifas eléctricas con fines agrícolas.

En vista de la necesidad de agua, pero también de aminorar los costos de la energía, la COPUDA inició desde 2007 la construcción de obras de infraestructura para la captación de agua, como pozos de infiltración, retenes, hoyas y pequeñas represas. Solo algunas acciones se inscribieron en el marco de programas gubernamentales en relación con el uso eficiente del agua y la energía eléctrica, y uso pleno de la infraestructura hidroagrícola (Olvera, 2007). No obstante, se realizaron predominantemente a través de su sistema comunitario de agua, y en su mayoría con recursos propios. Hasta ahora los pueblos han construido más de 250 pozos de infiltración, y en total más de 300 obras de captación (Flor y Canto, 2017). Tal situación demuestra la capacidad organizativa de los pueblos en su compromiso con un bien que forma parte de su cosmovisión e identidad. Así, desde 2009 las obras han tenido un impacto favorable sobre el acuífero.

Con base en que las condiciones que dieron origen al decreto de veda pudieron haber cambiado y de que la construcción de obras de captación por parte de los pueblos ha tenido resultados notorios y favorables en el nivel de agua en los pozos, la copuda, con el apoyo y la asesoría jurídica del Centro de Derechos Indígenas Flor y Canto, A.C, demandó a Conagua en el año 20ı2, a fin de que se valorara la pertinencia del decreto de veda de los años sesenta y, en su caso, fuera modificado.

Pasó más de un quinquenio de lucha por la vía legal, luego de que la Conagua intentara desconocer a los representantes de COPUDA, y de que desestimara la propuesta con argumentos de índole meramente administrativa y procedimental, cuando de fondo lo que se discute son las garantías constitucionales de los pueblos indígenas, como las que corresponden a la libre determinación y autonomía de los pueblos y comunidades indígenas, asentadas en el artículo $2^{\circ}$ constitucional.

La demanda de Copuda quedó fortalecida jurídicamente, una vez que procediera la reforma al marco constitucional en materia de derechos humanos del io de junio de 20II. Se dio un bloque de constitucionalidad a los tratados internacionales que amparan los derechos de los pueblos indígenas previstos, entre otros, en el Convenio I69 de la Organización Internacional del Trabajo, el cual establece el uso preferente de los pueblos indígenas sobre los recursos naturales en sus territorios y que su aplicación "debe ser de manera directa y sin restricción alguna por funcionarios de la administración pública" (Lagunes, 2012). 
El 8 de abril de 2013, la Primera Sala Regional Metropolitana del Tribunal de Justicia Fiscal y Administrativa emitió una resolución en la que mandató a la Conagua a iniciar un procedimiento en el cual valore la procedencia de la solicitud la Copuda para proponer al titular del Ejecutivo federal la modificación del Decreto de Veda de 1967, consultando a la comunidad y a los pueblos indígenas zapotecas del Valle de Ocotlán y Zimatalán de Álvarez (Tribunal Federal de Justicia Fiscal y Administrativa, 2013). No obstante, la Conagua se rehusó a realizar la consulta a los pueblos indígenas y pretendió cumplir con esta sentencia después de "consultar" al Consejo de Cuenca de la Costa de Oaxaca, en representación de la ciudadanía.

Este artificio político llevó a la copUdA, junto con la organización Flor y Canto, a denunciar el desacato de la Conagua, y a instar al desconocimiento del Consejo de Cuenca de la Costa de Oaxaca:

Así mismo también desconocemos al Consejo de Cuenca de la Costa de Oaxaca cotas A.C., toda vez que hace mención la Conagua que los estudios técnicos fueron presentados ante esta asociación para su conocimiento y sugerencia, ya que el COTAS no representa a las comunidades indígenas, mucho menos es participe dentro del proceso jurídico del cual el Tribunal reconoció que los derechos que han sido violados son a las comunidades y pueblos Zapotecas, con quien la Conagua tendría que estar trabajando para consultar a la comunidad y pueblos indígenas zapotecas del Valle de Ocotlán y Zimatlán de Álvarez, Oaxaca (сомda y Flor y Canto, 2014).

Sin poder evadir la presión política y jurídica, en 2015 la Conagua se vio obligada a iniciar el proceso de consulta indígena, que por sus características debe ser previa, libre e informada. Según el Protocolo de Consulta, esta se desarrollaría en cinco etapas: I) acuerdos previos; 2) informativa; 3) deliberativa; 4) consultiva; 5) ejecución y seguimiento de acuerdos.

Desde 2017 se ha venido desarrollando la etapa consultiva, durante la cual, tanto la COPUDA como la Conagua, han presentado propuestas para la modificación del decreto de veda de 1967. Cabe señalar que la representación de este organismo a nivel local, a cargo de Gabriel Kalid Mohamed Baez, director jurídico y actual coordinador de las actividades del Organismo de Cuenca Pacífico Sur, ha restado importancia a estas reuniones, tal como se constata en sus retrasos, ausencias, cambios de fecha, apremios para terminar las reuniones, es decir, se trata de un problema no solo de forma, sino de una sistemática actitud de desdén por parte de la autoridad hacia los pueblos indígenas. 
El dispositivo cultural de la cuenca ha estado presente en varios de los diálogos, llevando frecuentemente el debate a una discusión de índole jurídica-técnica-administrativa. Al ser este dispositivo hegemónico, en diferentes ocasiones la COPUDA ha hecho referencia a la cuenca; no obstante, la intención es hacer notar que la solución a la problemática debe examinarse a partir de integrar conocimientos.

La COPUDA ha enfrentado la imposibilidad política del manejo de la cuenca ante la necesidad del reconocimiento de los territorios indígenas, de los cuales dependen los pueblos, pero también de los cuales a esta escala se pueden hacer responsables, y así lo dejan asentado en su propuesta Xnizaa. Esta es la discusión de fondo en estos tiempos ¿De quién es el agua? ¿Quién realmente se hace responsable? ¿Quién tiene capacidad de decisión sobre esta? Porque en este caso, no todas las acciones están recayendo en el mismo actor.

\section{Conclusión}

Los casos de estudio examinados advierten que el modelo de gestión por cuencas impulsado en México reproduce el peso político e histórico del concepto de "cuenca" como dispositivo cultural en tres sentidos: I) naturaliza el espacio del agua, en tanto que la cuenca es una escala impuesta a las dinámicas sociopolíticas que determinan las problemáticas actuales; 2) se corresponde con la planeación de transformaciones radicales del espacio del agua, apegándose a poderosos intereses económicos; y, 3) mantiene su capacidad de catalizador político al desmantelar proyectos espaciales previos al de su institucionalización, incluso de los sistemas construidos sobre bases ancestrales, como es el manejo comunitario del agua.

En los dos primeros casos los datos muestran una clara relación entre problemáticas regionales (abasto urbano, disponibilidad y contaminación), grupos de poder (ANEAs, Grupo Lala, entre otros) y las decisiones tomadas en los consejos de cuenca, sin la representación cabal de los actores y usuarios. En el último, se advierte la inoperancia del consejo para tratar una problemática que exhibe la desventaja social, económica y política que enfrentan las poblaciones indígenas como las que integran la COPUDA, excluidas del acceso al vital líquido para sus actividades de subsistencia.

En suma, el manejo del agua por cuencas hidrológicas debe considerar de manera ineludible los factores sociales que intervienen en ellas, a fin de proveer del vital líquido en condiciones de equidad y de estabilidad social y ambiental. 


\section{Bibliografía}

Angeles, Gabriela, María Perevotchikova y Joel Carrillo

2008 "Posibles Controles Hidrogeológicos de Impacto Ambiental por la Extracción de Agua Subterránea en Xochimilco. México", Journal of Latin American Geography, 7(I), pp+39-56.

Buache, Phillippe

I772 Géographie élémentaire moderne et ancienne: contenant les principes de la géographie: une description générale du globe, París: Mgr. le duc d'Órléans.

Gobierno de la Ciudad de México

2016 Estrategia de Resiliencia de la CDMX, México.

Conagua

2000 Programa hidráulico de gran visión 2001-2020, para la Región Hidrológica 36, Nazas Aguanaval, marco de referencia, problemática sustantiva y alternativas de solución para la gestión integral de la Región Hidrológica 36, México.

Conagua,

2003 Programa Hidráulico Regional, 2002-2006. Cuencas centrales del norte. Región VII, México.

Conagua

2010 Vedas de agua subterránea en México, México.

Conagua

2012 ${ }^{\mathrm{a}}$ Atlas del agua en México, México.

Conagua

2012b Programa Hidrico Regional Visión 2030 Región Hidrológico-Administrativa vir Cuencas Centrales del Norte, México.

Conagua

2013 Programa Hidrico Regional Visión 2030 Región Hidrológico-Administrativa XIII Aguas del Valle de México, México.

Conagua

2014 Programa de medidas preventivas y de mitigación de la sequí. Consejo de Cuenca Costa de Oaxaca, México.

Conagua

20I5 $5^{\mathrm{a}}$ Actualización de la disponibilidad media anual de agua en el acuifero Zona Metropolitana de la Ciudad de México (0901),Distrito Federal, México. 


\section{Conagua}

2015b Actualización de la disponibilidad media anual de agua en el acuífero Principal-Región Lagunera (0523) Coabuila, México.

Conagua

2015c Atlas del Agua en México, México.

Conagua

2015d Estadisticas Agrícolas de los Distritos de Riego Año Agrícola 2013-2014, México.

\section{Conagua}

2016 Grandes retos hidricos en el Valle de México, México.

Conagua

2017 Consejos de Cuenca, México. Dor* http://files.conagua.gob.mx/transparencia/Generalidades_Jun2017.pdf

Crampton, Jeremy y Stuart Elden (eds.)

2016 Space, Knowledge and Power, Foucault and Geography, Nueva York: Routledge (e-book).

Consejo Nacional de Investigación,

i995 El Agua y la Ciudad de México, México.

\section{COPUDA}

s.a. Xnizaa (nuestra agua), Oaxaca: Centro de Derechos Indígenas Flor y Canto A.C. DoI: https://www.oxfammexico.org/sites/default/files/ Propuestacopuda-.pdf

copuda y Flor y Canto, A.C.

2014 "Denuncian a Conagua Oaxaca por desacato", México, DoI: http://eoaxaca.com/nota/2014-07-07/sociedad/denuncian-conagua-oaxaca-por-desacato.

\section{Coronel, Dolores}

2006 "Zapotecos de los valles centrales de Oaxaca”, en: Pueblos indígenas del México contemporáneo. Comisión Nacional para el Desarrollo de los Pueblos Indígenas (CNPI), México.

Deming, David

2013 "Pierre Perrault, the Hidrologic Cycle and the Scientific Revolution", Groundwater, 52(I), pp. I56-I62.

Dooge, James

$200 \mathrm{I}$ "Concepts of the hydrological Cycle. Ancient and modern". International Symposium OH2 'Origins and History of Hydrology'. Mayo, pp. 9-II. URL: http://hydrologie.org/АCт/оH2/actes/o3_dooge.pdf 
El Economista

2017 "Valle de México concentra $25 \%$ de la actividad económica nacional", I8 de enero.

Flor y Canto A.C.

2017 "Somos campesinos y campesinas sembradores de agua y vida", I5 de diciembre. URL: http //cdiflorycanto.org/web/2017/12/15/3046/

Foucault, Michael

2007 El nacimiento de la Biopolítica, Buenos Aires: Fondo de Cultura Económica.

Foucault, Michael

2009 Security, Territory, Population, Nueva York: Palgrave MacMillan.

Foucault, Michael

I980 Power/Knowledge, Nueva York: Pantheon Books.

Foucault, Michael

1996 La verdad y las formas jurídicas, Barcelona: GEDISA, URL; http://www. hechohistorico.com.ar/archivos/Foucautl\%20-\%20La\%2overdad\%20 y\%2olas\%2oformas\%2ojur\%C3\%ADdicas.pdf

Geddes, Patrick

I923 The valley section from bills to sea, New York City. URL;//habitat.aq.upm. es/boletin/n45/apged.en.html

González, Arsenio

2016 La región bidropolitana de la Ciudad de México, México: Instituto Mora. Harvey, David

I974 "The Population, Resources and the Ideology of Science", Economic Geography, 5o(3), pp. 256-277.

Harvey, David

2009 Espacios del capital. Hacia una geografía crítica, Madrid: Akal.

Hernández, Cleotilde

201 "Nueva política del agua y herencias centralizadoras: el consejo de cuenca del Valle de México", Agricultura, sociedad y desarrollo, 8(3), pp. 303-327. URL; http://www.colpos.mx/asyd/volumen8/numero3/asdI0-027.pdf

Hubbart, Jason

201 "Origins of Quantitative Hydrologyः Pierre Perrault, Edme Mariotte, and Edmond Halley", Water Resources IMPACT, I3(6), pp. I5-I7. 
Huxley, Margo

2016 "Geographies of governmentality”, en Crampton, Jeremy y Stuart Elden (eds.), Space, Knowledge and Power, Foucault and Geography, Nueva York: Routledge (e-book).

IFAI

2012 Recurso de revisión, Exp. RR.SIP.1732/2012, México.

Kauffer, Edith

20 "Hidropolítica del Candelaria: del análisis de la cuenca al estudio de las interacciones entre el río y la sociedad ribereña", Revista Relaciones, El Colegio de Michoacán, México, 3I(124), pp. 187-226.

Lagunes, Ricardo

2012 "La reforma constitucional en derechos humanos y los pueblos indígenas", La Jornada, 27/I2/20I2, URLः http //www.jornada.unam. $\mathrm{mx} / 2012 / \mathrm{I} 2 / 27 /$ opinion/oriarpol (Consulta 4/oI/20I7).

Lefebvre (Henry)

I974 "La producción del espacio", Revista de sociología, vol. 3, pp. 219-229.

Legg, Stephen

2005 "Foucault's Population Geographies: Classifications, Biopolitics and Governmental Spaces", Population, Space and Place, vol. II, pp. 137-I56, en www.interscience.wiley.com, DOI: http*//dx.doi,org/IO.IOO2/psp+357 (Consulta 2/12/2016).

Mc Callam, David

$20 I I$ "Quelques reflexions sur la figure de la chaine au XVIII ${ }^{\mathrm{E}}$ siecle: en theorie et en pratique”, en: Valérie Koby (ed.), De la théorie à l'action. Les savoirs et leur mise en œuvre au siècle des Lumières, Ginebra: Slaktine Reprints, Pp. I23-I34.

Melville, Roberto

2000 "La Cuenca fluvial como territorio fragmentado para la organización del aprovechamiento de los recursos hídricos", en C. Scott, P. Wester y B. Marañón (eds.), Asignación, manejo y productividad de los recursos hidricos en Cuencas, México: International Water Mangement Institute, pp. 57-73.

Olvera, Sonia

2007 Experiencias de manejo y conservación del acuífero de valles centrales de Oaxaca, tesis de licenciatura, Universidad Autónoma del Estado de Hidalgo, México. 
Perrault, Pierre

I674 De l’origine des fontaines, París: Pier le Petit.

Philo, Chris

2000 "Foucault's Geography", en: Crang, Mike y Thrif, Nigel. Thinking Space, Nueva York: Routledge, pp. 205-238.

Ratzel, Friedrich

I885 Anthropogeographie öder Grundzüge der Erdkunde auf die Geschischite, Stuttgart: J. Engelhorn.

Reclus, Elisse

I869 Histoire d’un ruisseau, París: J. Hetzel y Cie.

Rodríguez, Lilia y Jorge Armando Morales

2013 "Integración de un sistema de cuentas económicas e hídricas en la Cuenca del Valle de México", Realidad Datos y Espacio, vol. 4, núm. I, pp. 72-89.

Rutherford, Stephanie y Paul Rutherford

2013 "Geography and Biopolitics", Geography Compass, 7(6), pp. 423-434.

Sagarpa

2010 Anuario Estadistico de la Región Lagunera, 2010, México.

Sagarpa

2015 "Tiene cuenca lechera de la comarca una producción diaria de casi 9 millones de litros", México. URL: http://www.sagarpa.gob.mx/Delegaciones/regionlagunera/boletines/Paginas/2015Bo36.aspx.

Sánchez, Álvaro

2010 "Delimitación geográfica”, en Álvaro López y Álvaro Sánchez (eds.), Comarca Lagunera, procesos regionales en el contexto global, México: Instituto de Geografía-unAm, pp. 15-36.

Swyngedouw, Eric

2004a Social power and the urbanization of water: flows of power, Oxford: Oxford University Press.

Swyngedouw, Eric

2004 b "Scaled geographies: Nature, place, and the politics of scale", Scale and geographic inquiry: Nature, society, and method, Reino Unido: Blackwell, Pp. I29-I53.

SHCP

2015 Cuenta de la Hacienda Pública Federal de 2015, México. url: http:// finanzaspublicas.hacienda.gob.mx/work/models/CP/20I5/tomo/III/ PEJ+06.IIFMA.pdf 
Tribunal Federal de Justicia Fiscal y Administrativa

2013 Cumplimiento de la Sentencia contra la Conagua promovida por Justino Martínez y otros, México. URL: http://aguaparatodos.org.mx/wp-content/uploads/cumplimiento-de-la-sentencia.pdf.

Zwarteveen Margaret y Rutgerd Boelens

2014 "Defining, researching and struggling for water justice: some conceptual building blocks for research and action", Water International, 39(2), pp. I43-158.

Lourdes Romero Navarrete

Doctora en Historia por la unam. Profesora-Investigadora del Centro de Investigaciones y Estudios Superiores en Antropología Social, Ciudad de México. Entre sus publicaciones está: Ma. Concepción Martínez y Lourdes Romero Navarrete (coords.) (2016). Agua e Historia Estado, conflictos e impactos ambientales. Experiencias regionales, siglos XIX-XXI. México: Instituto Mora; Romero, Lourdes (20I7)."El reparto agrario de 1936 en La Laguna (Coahuila-Durango): arena política, sindicalismo y acción pública en la instauración de la propiedad ejidal". Enः Antonio Escobar, Zulema Trejo y José, Ángel Rangel Silva. El mundo rural en la transición del siglo XIX al siglo XX. México: CIESAS-COLSON-IRD, 343-372. Romero, Lourdes (2016). "Participación y legislación sobre agua en México. Una aproximación histórica". Agua y Territorio. Universidad de Jaén, España. 7: 22-34. Responsable de la línea de especialización Agua, Sociedad y Cultura del Posgrado en Antropología, ciesas, Ciudad de México. Correo electrónico: lourdesr@ciesas.edu.mx. orcid: https:// orcid.org/0000-0003-4292-8387

Mónica Olvera Molina

Doctora en Geografía por la Universidad Nacional Autónoma de México, actualmente coordina el proyecto Promoviendo el Acceso Equitativo al Agua en México del Programa de Bienes Comunes Naturales, oxfam México. Bajo un enfoque de investigación-acción sus líneas de interés han sido la producción política del espacio del agua en relación con la construcción de megaproyectos de presas, la historia política de la cuenca y los conflictos sociales por el agua. Actualmente en el contexto del proyecto que coordina enfatiza la problemática de desigualdad y captura política en el modelo de gestión actual. Ha publicado diversos artículos 
en torno a la cuenca como un espacio hidrosocial, el más reciente de los cuales es Desnaturalizando la cuenca en México: Notas sobre el espacio hidropolítico. Agua y Territorio. (7). Universidad de Jaén, España. Olvera, Mónica (2016).“Megaproyectos de presas en México: Del desplazamiento forzado a la resistencia, 1950-2012”, en Megaproyectos en México en el siglo xx. México: Ítaca- Facultad de Filosofía y Letras, UNAM. monicaolvera@oxfammexico.org

Citar como: Lourdes Romero Navarrete y Mónica Olvera Molina (2019), "Control del agua bajo el modelo de gestión por cuencas hidrológicas en México", Iztapalapa. Revista de Ciencias Sociales y Humanidades, núm. 86, año 40, enero-junio de 20I9, ISSNः 2007-9176; pp. 25-158. Disponible en $<$ http://revistaiztapalapa.izt.uam.mx/index.php/izt/issue/archive $>$. 